\title{
Four-dimensional, flow-sensitive magnetic resonance imaging of blood flow patterns in thoracic aortic dissections
}

\author{
Christopher J. François, MD, ${ }^{a}$ Michael Markl, PhD, ${ }^{\text {b,c }}$ Mark L. Schiebler, MD, ${ }^{\text {a }}$ Eric Niespodzany, MS, ${ }^{a}$ \\ Benjamin R. Landgraf, BS, ${ }^{a}$ Christian Schlensak, MD, ${ }^{\mathrm{d}}$ and Alex Frydrychowicz, $\mathrm{MD}^{\mathrm{a}, \mathrm{e}}$
}

\begin{abstract}
Objective: The purpose of this study was to evaluate alterations in flow patterns in thoracic aortic dissections using 4-dimensional, flow-sensitive magnetic resonance imaging.

Methods: This prospective study was conducted at 2 academic tertiary referral medical centers. Thirteen 4-dimensional flow magnetic resonance imaging studies were performed in 12 subjects (4 female, aged 25-71 years) with thoracic aortic dissection using 3.0T clinical scanners. Qualitative assessment of flow patterns in the true and false lumina was performed in consensus by 3 cardiovascular radiologists. Quantitative analysis included measurement of net flow, retrograde flow, peak flow, and time-to-peak flow in the true and false lumina in the ascending aorta, aortic arch, and descending aorta. Differences in flow through the true and false lumina at each analysis plane were compared with the 2-tailed, paired Student $t$ test.
\end{abstract}

Results: Flow patterns were significantly altered in association with different extents of disease, vessel dilatation, and post-therapeutic anatomy. Total flow per cardiac cycle and peak flow were higher in the true lumen than in the false lumen $(P<.01)$. Retrograde flow was less in the true lumen than in the false lumen $(P \leq .01)$. Timeto-peak flow in the true lumen occurred later than in the false lumen $(P=.05-.08)$.

Conclusions: Four-dimensional, flow-sensitive magnetic resonance imaging at 3.0T provided qualitative and quantitative information on alterations of aortic flow in patients with thoracic aortic dissection. Future application of this magnetic resonance flow methodology may help provide insights into the pathophysiology and effects of flow alterations and establish prognostic indicators for the development of complications or aneurysm growth in patients with aortic dissection. (J Thorac Cardiovasc Surg 2013;145:1359-66)

Thoracic aortic dissections are a life-threatening condition with an estimated 10 -year survival of $35 \%$ to $75 \%$. However, there are striking differences in outcomes between patients with complicated and uncomplicated dissection. Common risk factors, conditions, and stratified outcomes associated with aortic dissection have been published by the International Registry of Acute Aortic Dissection. ${ }^{1-4}$ When the dissection involves the ascending aorta (DeBakey I and II; Stanford type A), ${ }^{5,6}$ emergency

\footnotetext{
From the Department of Radiology, ${ }^{\text {a }}$ University of Wisconsin-Madison, Madison, Wis; Department of Radiology, ${ }^{\mathrm{b}}$ Medical Physics, University Hospital Freiburg, Freiburg, Germany; Department of Radiology, ${ }^{\mathrm{c}}$ Northwestern University, Chicago, Ill; Department of Cardiothoracic Surgery, ${ }^{\mathrm{d}}$ University Hospital Freiburg, Freiburg, Germany; and Department of Radiology and Nuclear Medicine, ${ }^{\mathrm{e}}$ University Hospital Schleswig-Holstein, Lübeck, Germany.

Funding: M.M. received funding from "Deutsche Forschungsgemeinschaft" Grant MA 2383/5-1 and "Bundesministerium für Bildung und Forschung" Grant 01EV0706. A.F. received an educational stipend from Bracco Diagnostics. C.F., E.N., and B.L. received funding from National Institutes of Health Grant 2R01HL072260. The Department of Radiology, University of Wisconsin-Madison receives research support from GE Healthcare.

Disclosures: Authors have nothing to disclose with regard to commercial support.

Received for publication April 20, 2012; revisions received June 21, 2012; accepted for publication July 10, 2012; available ahead of print July 30, 2012.

Address for reprints: Christopher J. François, MD, Cardiovascular and Chest Sections, Department of Radiology, University of Wisconsin, School of Medicine and Public Health, 600 Highland Avenue, Madison, WI 53562 (E-mail: cfrancois@uwhealth.org).

$0022-5223 / \$ 36.00$

Copyright (c) 2013 by The American Association for Thoracic Surgery

http://dx.doi.org/10.1016/j.jtcvs.2012.07.019
}

surgical repair of the ascending aorta is required. If the ascending aorta is not affected (DeBakey III; Stanford type B), ${ }^{5,6}$ uncomplicated cases can usually be initially managed with medical therapy. ${ }^{7}$ When type A dissections extend into the descending thoracic aorta, the residual dissection affecting the arch and descending aorta is typically managed medically if it is uncomplicated. Patients with repaired type $\mathrm{A}$ and $\mathrm{B}$ dissections treated medically require frequent follow-up imaging to monitor for development of complications. These complications include aortic aneurysm growth, rupture, end-organ malperfusion, persistent severe pain, and refractory hypertension. Unfortunately, up to $30 \%$ of patients with type B dissections initially managed with antihypertensive medication will eventually require intervention, ${ }^{8}$ with the majority of these procedures performed during the first year of follow-up. The capability to accurately predict which patients will develop complicated aortic dissection could transform clinical management by allowing earlier treatment before irreversible end-organ ischemia or frank aortic rupture.

However, data on parameters (clinical or imaging findings) that can be used to help predict the risk of complications after initial management are limited. Imaging features that have been associated with a poorer prognosis include partial thrombosis of the false lumen (FL), atherosclerosis, and aortic aneurysm. ${ }^{3}$ Our current understanding is limited with respect to the progression and time course of 


$$
\begin{aligned}
& \text { Abbreviations and Acronyms } \\
& \begin{aligned}
\mathrm{FL} & =\text { false lumen } \\
4 \mathrm{D} & =4 \text {-dimensional } \\
\mathrm{MR} & =\text { magnetic resonance } \\
\mathrm{MRI} & =\text { magnetic resonance imaging } \\
\mathrm{PC} & =\text { phase contrast } \\
3 \mathrm{D} & =3 \text {-dimensional } \\
\mathrm{TL} & =\text { true lumen } \\
\text { 2D } & =2 \text {-dimensional }
\end{aligned}
\end{aligned}
$$

chronic dissections. Of note, there are no markers or hemodynamic studies that help to predict the clinical behavior of acute and chronic dissections.

Previous studies using echocardiography ${ }^{9}$ and 2-dimensional (2D) phase contrast (PC) magnetic resonance imaging (MRI ${ }^{10-12}$ have shown differences in the flow patterns in the true lumen (TL) and FL. Data from these studies suggest that differences in flow patterns and flow hemodynamics may be important in predicting acute complications and determining the outcomes of chronic dissections. However, these techniques had only limited coverage of the aorta and are limited to imaging a single 2D plane. Recently improved Cartesian ${ }^{13}$ and radial ${ }^{14}$ 4-dimensional (4D) flow-sensitive velocity mapping techniques (4D flow MRI) have been used for the evaluation of flow patterns with a larger, volumetric field of view. The purpose of this study was to qualitatively and quantitatively assess the flow in patients with thoracic aortic dissection at 2 centers using 4D flow MRI.

\section{MATERIALS AND METHODS}

Studies were performed according to protocols approved by the review boards of each institution. Individually identifiable health information was protected according to Health Insurance Portability and Accountability Act regulations. Patients were recruited when referred for imaging of aortic dissection. Ten subjects were recruited from the University of Wisconsin-Madison, and 2 subjects were recruited from University Hospital Freiburg. Subject demographics are summarized in Table 1.

\footnotetext{
Magnetic Resonance Acquisition

University of Wisconsin-Madison. Ten subjects were enrolled (aged $51 \pm 18$ years and weighing $63.4 \pm 14.0 \mathrm{~kg} ; 6$ male and 4 female). In these 10 subjects, a total of 11 magnetic resonance (MR) examinations were performed. One subject was imaged twice after a time interval of 8 months (Table 1). Scan 1 (subject 5) was performed after type A dissection treated by a Bentall procedure. The subject was imaged again (subject 11) before treatment of an enlarging thoracoabdominal aortic aneurysm. Therefore, the second scan was considered independently. MRI studies were performed on a clinical 3.0T scanner (TRIO, Siemens Healthcare, Erlangen, Germany) with an 8-channel, phased-array body coil. 4D flow MRI was performed with a referenced, 4-point, Cartesian PC sequence with velocity encoding in all 3 spatial directions. Prospective electrocardiogram gating and adaptive navigator gating (crossed pair navigators monitoring the position of the diaphragm) for compensation of breathing motion led
}

to imaging times of 12 to 18 minutes. ${ }^{13}$ Sequence parameters were adapted to each individual's anatomy: field of view $=210$ to $260 \times 320$ to 400 $\mathrm{mm}^{2}$; matrix $=74$ to $88 \times 192$; repetition time $=6.1 \mathrm{~ms}$; echo time $=3.7 \mathrm{~ms}$; flip angle $=15$ degrees; velocity encoding $=150 \mathrm{~cm} / \mathrm{s}$. The temporal resolution was $48.8 \mathrm{~ms}$. Data processing included intrinsic corrections for Maxwell terms, eddy currents, and velocity aliasing (4 cases). In one of the examinations with aliasing, residual aliasing could not be removed entirely. In 9 of 11 examinations, 4D flow MRI was performed after the administration of intravenous gadobenate dimeglumine (Bracco Diagnostics, Princeton, NJ) at $0.1 \mathrm{mmol} / \mathrm{kg}$ body weight, given for clinical purposes.

University Hospital Freiburg. Two male subjects were enrolled (aged 40 and 50 years and weighing 72.6 and $137.4 \mathrm{~kg}$ ). Studies were acquired at 3.0T (MR750, GE Healthcare, Waukesha, Wis) with a 32channel, phased-array body coil (NeoCoil, Pewaukee, Wis). 4D flow MRI was performed using a 5-point ${ }^{15}$ balanced 3-directional velocity encoding sequence with PC vastly undersampled isotropic projection reconstruction. ${ }^{14}$ By using retrospective electrocardiogram gating and adaptive navigator gating for compensation of breathing motion, scan times were 9 to 14 minutes. Sequence parameters were adapted to each individual's anatomy: field of view $=320$ to $360 \mathrm{~mm}^{3}$; matrix $=256^{3}$; resulting isotropic spatial resolution 1.25 to $1.4 \mathrm{~mm}^{3}$, repetition time $=6.2 \mathrm{~ms}$; echo time $=2.1 \mathrm{~ms}$; flip angle $=10$ degrees; velocity encoding $=150$ to 250 $\mathrm{cm} / \mathrm{s}$. Data with a nominal temporal resolution of $4 \times$ repetition time (24.8-40.4 ms) were reconstructed to 20 time frames to limit the data volume for facilitated handling. Data processing included intrinsic corrections for Maxwell terms and eddy currents. In both cases, 4D flow MRI was performed after the administration of intravenous gadobenate dimeglumine (Bracco Diagnostics) at $0.1 \mathrm{mmol} / \mathrm{kg}$ bodyweight, given for clinical purposes.

\section{Image Processing}

A velocity-weighted MR angiogram was calculated and noise masking was performed with MatLab-based, home-built software (The MathWorks, Inc, Natick, Mass). Data were then converted for visualization with EnSight (CEI, Apex, NC). A shaded surface display was created on the basis of the MR angiogram. Four analysis planes transecting the aortic lumen orthogonal to the anticipated main flow direction were manually placed (Figure 1) in the (1) ascending aorta, (2) proximal arch, (3) distal aortic arch, and (4) descending aorta to the caudal-most extent of the imaged volume. This defined 4 segments of the aorta (analysis plane 1-2: segment a; analysis plane 2-3, segment b; analysis plane 3-4, segment c; analysis plane 4 downstream to the end of the covered data volume, segment d). The 4 planes were used to emit 3-dimensional (3D) time-resolved particle traces and 3D streamlines (Figures 1 and 2). Although it was not recorded, the amount of time to perform the post-processing of the data from the time of image acquisition to generation of streamlines and particle traces is approximately 45 to 60 minutes when performed by a trained and experienced user of the software.

\section{Qualitative Analysis}

Streamlines and particle traces were viewed dynamically and rotated or magnified for inspection in any chosen orientation such that all readers could take advantage of the full 3D and time-resolved nature of the data (EnLiten; CEI Software, Apex, NC). 4D flow MRI datasets were reviewed in a consensus reading with 3 cardiovascular radiologists, 2 with longstanding experience with hemodynamic analyses. 4D flow MRI datasets were not reviewed independently. During image analysis, clinically performed computed tomography and additional contrast-enhanced MR angiography scans were available for confirmation of findings. The segmentation and visualization quality were visually determined on a 4-point Likert scale ( 0 = poor, $1=$ okay, $2=$ good, $3=$ excellent). All 4 (a-d) segments were evaluated for helicity (presence, direction) and signs 
TABLE 1. Subject demographics

\begin{tabular}{|c|c|c|c|c|c|c|c|c|}
\hline Subject & $\begin{array}{l}\text { Age at } \\
\text { 4D flow } \\
\text { MRI }\end{array}$ & Gender & Diagnosis & Extent & $\begin{array}{c}\text { FL } \\
\text { thrombosis }\end{array}$ & Procedure & $\begin{array}{l}\text { MRI before } \\
\text { or after } \\
\text { procedure }\end{array}$ & $\begin{array}{c}\text { Time } \\
\text { between } \\
\text { procedure } \\
\text { and MRI }\end{array}$ \\
\hline 1 & $26 y$ & M & Type A dissection & Arch & None & Bentall procedure & After & $1 \mathrm{mo}$ \\
\hline 2 & $52 \mathrm{y}$ & M & $\begin{array}{l}\text { TAAA after type } \\
\text { B dissection }\end{array}$ & Arch to renal arteries & Partial & TEVAR & Before & $1 \mathrm{mo}$ \\
\hline 3 & $69 \mathrm{y}$ & M & Type A dissection & Arch to LCIA and RCIA & None & Open AAo repair & After & $1 \mathrm{mo}$ \\
\hline 4 & $71 \mathrm{y}$ & M & $\begin{array}{l}\text { Traumatic type } \\
\text { A dissection }\end{array}$ & Distal arch to LCIA, REIA & None & $\begin{array}{l}\text { Open repair for newly developed } \\
\text { TAA }\end{array}$ & After & $10 \mathrm{mo}$ \\
\hline $5^{*}$ & $25 \mathrm{y}$ & M & $\begin{array}{l}\text { Type A dissection, } \\
\text { Marfan syndrome }\end{array}$ & $\begin{array}{l}\text { Proximal arch to aorta } \\
\text { bifurcation }\end{array}$ & None & $\begin{array}{l}\text { Bentall procedure, open repair for } \\
\text { newly developed TAAA }\end{array}$ & Before & $1 \mathrm{mo}$ \\
\hline 6 & $71 \mathrm{y}$ & $\mathrm{F}$ & Type A dissection & Proximal arch to LCIA & Partial & $\begin{array}{l}\text { Open valve-sparing AAo } \\
\text { replacement }\end{array}$ & After & $5 \mathrm{y}$ \\
\hline 7 & $51 \mathrm{y}$ & $\mathrm{F}$ & $\begin{array}{l}\text { Type A dissection, } \\
\text { Marfan syndrome }\end{array}$ & $\begin{array}{l}\text { Proximal descending to } \\
\text { mid-infrarenal aorta }\end{array}$ & Partial & $\begin{array}{l}\text { Open valve-sparing AAo } \\
\text { replacement }\end{array}$ & After & $18 \mathrm{y}$ \\
\hline 8 & $61 \mathrm{y}$ & $\mathrm{F}$ & Type A dissection & Proximal arch to LRA & Partial & $\begin{array}{l}\text { Open valve-sparing AAo } \\
\text { replacement }\end{array}$ & After & $6 y$ \\
\hline 9 & $59 \mathrm{y}$ & M & Type A dissection & Distal arch to LCIA, REIA & None & $\begin{array}{l}\text { Open valve-sparing AAo } \\
\text { replacement, arch } \\
\text { reconstruction }\end{array}$ & After & $3 y$ \\
\hline 10 & $50 \mathrm{y}$ & $\mathrm{F}$ & Type A dissection & $\begin{array}{l}\text { Proximal arch to mid } \\
\text { infrarenal aorta }\end{array}$ & None & $\begin{array}{l}\text { Open valve-sparing AAo } \\
\text { replacement }\end{array}$ & After & $5 \mathrm{mo}$ \\
\hline $11 *$ & $26 y$ & M & $\begin{array}{l}\text { Type A dissection, } \\
\text { Marfan }\end{array}$ & $\begin{array}{l}\text { Proximal arch to mid } \\
\text { descending aorta }\end{array}$ & None & $\begin{array}{l}\text { Bentall procedure, prior open } \\
\text { TAAA repair }\end{array}$ & After & $7 \mathrm{mo}$ \\
\hline 12 & $40 \mathrm{y}$ & M & Type B dissection & Distal arch to diaphragm & Partial & $\begin{array}{l}\text { Open repair for recurrent } \\
\text { symptoms while on medical } \\
\text { therapy }\end{array}$ & Before & $1 \mathrm{~d}$ \\
\hline 13 & $51 \mathrm{y}$ & M & $\begin{array}{l}\text { Type A dissection, } \\
\text { bicuspid aortic } \\
\text { valve }\end{array}$ & Proximal arch to LEIA, REIA & None & Bentall procedure & After & $24 \mathrm{mo}$ \\
\hline
\end{tabular}

4D, 4-dimensional; $M R I$, magnetic resonance imaging; $F L$, false lumen; TAAA, thoracoabdominal aortic aneurysm; TEVAR, thoracic endovascular aneurysm repair; $L C I A$, left common iliac artery; RCIA, right common iliac artery; AAo, ascending aorta; REIA, right external iliac artery; TAA, thoracic aortic aneurysm; $L R A$, left renal artery; $L E I A$, left external iliac artery. The Bentall procedure includes composite graft replacement of the aortic valve, aortic root, and ascending aorta with reimplantation of the coronary arteries. * Subjects 5 and 11 are the same patient scanned on 2 separate occasions.

of disturbed particle traces or streamlines (eg, additional helical and vortical flow patterns). For each analysis plane (1-4) and segment (a-d), the presence or absence of a TL and an FL was denoted. Segments that partially covered a dissection were counted as dissected. For all segments, the velocity of flows in TL and FL was compared on the basis of streamlines color coded to the absolutely measured velocities and recorded as faster or equally fast during maximum systole and early diastole. In addition, the presence of retrograde flow $(0=$ no, $1=$ minor, $2=$ major $)$ and its principal orientation (straight/laminar vs vortical/disturbed) and timing of FL retrograde flow were evaluated.

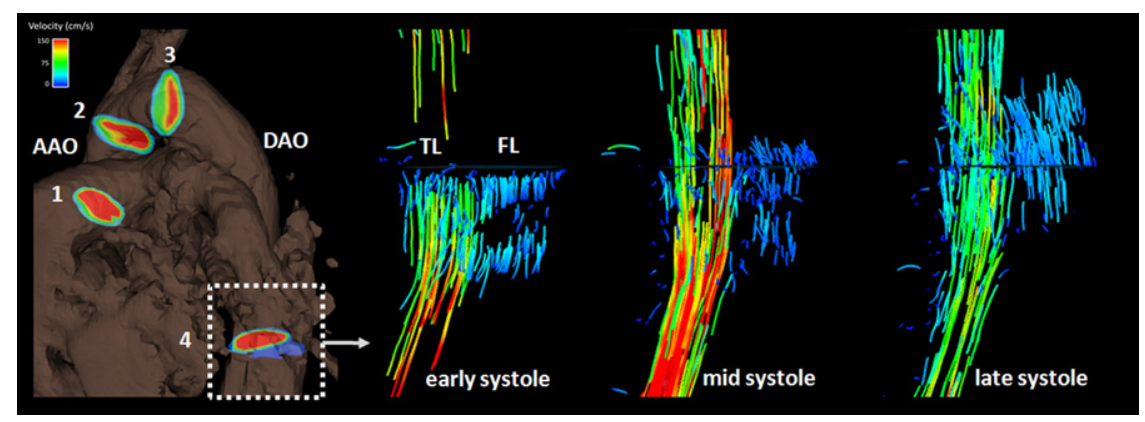

FIGURE 1. A 62-year-old woman with repaired type A aortic dissection. Surface-shaded display demonstrating locations of cut planes (1) in the ascending aorta, (2) proximal arch, (3) distal arch, and (4) mid-descending aorta, used for emitting particle traces and streamlines. Flow patterns at each of these cut planes and within 4 regions were evaluated: between planes 1 and 2, between planes 2 and 3, between planes 3 and 4, and distal to plane 4. Particle trace visualization during early, mid, and late systole revealed early backward flow (open arrow) in the FL. AAO, Ascending aorta; $D A O$, descending aorta; $T L$, true lumen; $F L$, false lumen. 


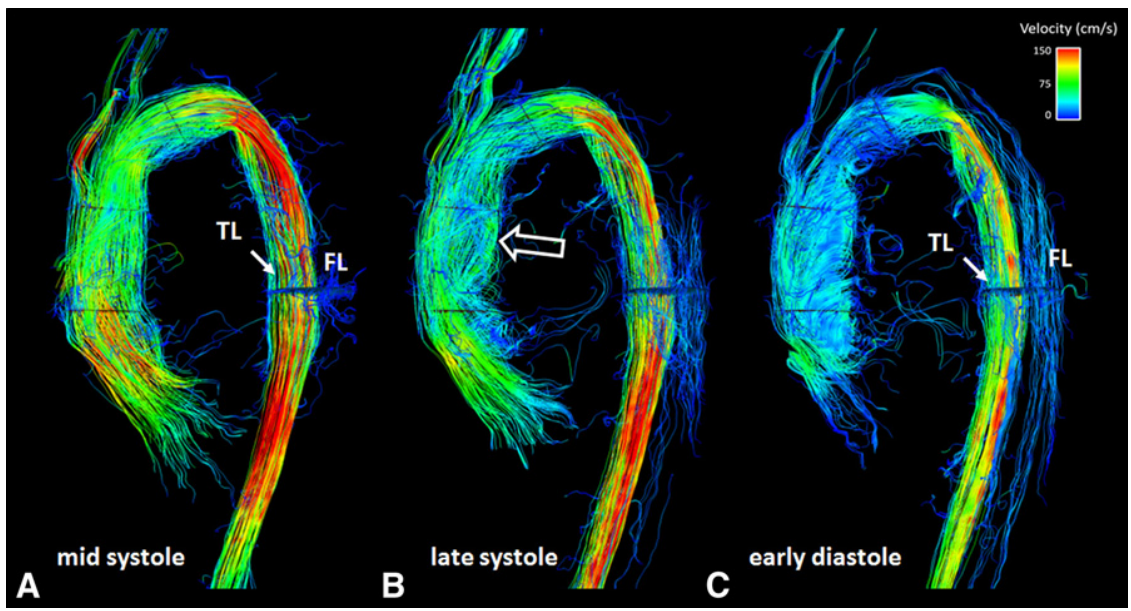

FIGURE 2. A 69-year-old man with repaired type A aortic dissection. Color-coded streamline visualization during (A) mid-systole, (B) late systole, and (C) early diastole shows the differences in flow patterns in the TL and FL. TL, True lumen; FL, false lumen.

\section{Quantitative Analysis}

Quantitative flow analysis was performed with a previously described MatLab-based home-built software (The MathWorks, Inc). ${ }^{16}$ At each analysis plane, the aorta was segmented manually at each time frame. For analysis planes containing dissection, the TL and FL were segmented separately. Net flow, retrograde flow, peak flow, and time-to-peak flow were measured at each of the analysis planes.

\section{Statistical Analysis}

For statistical analysis, the differences in each of the flow parameters through the TL and FL at each location were considered separately. A 2-tailed, paired Student $t$ test was used to assess statistical significance. This small study was conducted as a hypothesis-generating, rather than confirmatory, study. Qualitative data were used for descriptive purposes only. The statistical analysis was conducted in Excel 2007 (Microsoft Corp, Redmond, Wash).

\section{RESULTS}

\section{Qualitative Analysis}

Image quality of 4D flow MRI studies was good (2/13) to excellent (11/13) in all cases. The small numbers of volunteers enrolled at the University Hospital Freiburg, the lack of a cross-over comparison, and overall high-quality scores did not allow for an in-depth comparison of the techniques used at both institutions.

The TL and FL could be differentiated in 11 of 13 studies on the basis of the presence of slower flow in the FL than in the TL (Figures 2 and 3 ). The 2 other subjects presented with large aneurysms and high flow velocities such that a chronic, fenestrated dissection with aneurysm formation was assumed. Although the dissection could be clearly identified on the basis of differences in flow velocities in the TL and FL, the streamlines and particle traces did not completely fill the FL throughout the cardiac cycle in 12 of 13 of the studies (Figure 2).

Helicity, defined as corkscrew-like motion of the particle traces and streamlines, was present in 36 of 52 segments. We observed a tendency toward physiologic left-handed helicity in segment $\mathrm{A}(8 / 13)$ shifted toward right-handed flow in segments B and C (B: 11/13, C: 10/13) to nondiscernible helicity in segment $\mathrm{D}(10 / 13)$. A total of 25 additional vortices (Figures 4 and 5) and helices were seen in 11 of 13 studies.

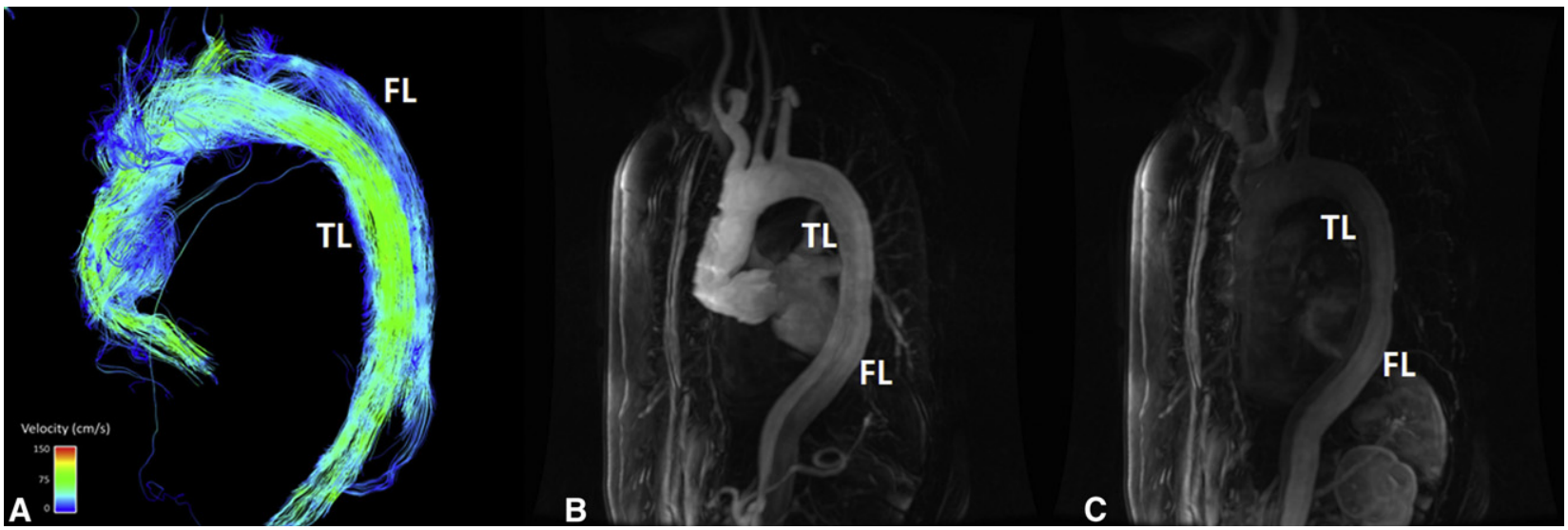

FIGURE 3. A 51-year-old man with chronic repaired type A aortic dissection. A, Color-coded streamline visualization during mid-systole revealing slow flow through the FL relative to the TL, as also seen on 2 subtracted maximum intensity projection images (B and C) acquired with time-resolved contrastenhanced MRA. $T L$, True lumen; $F L$, false lumen. 


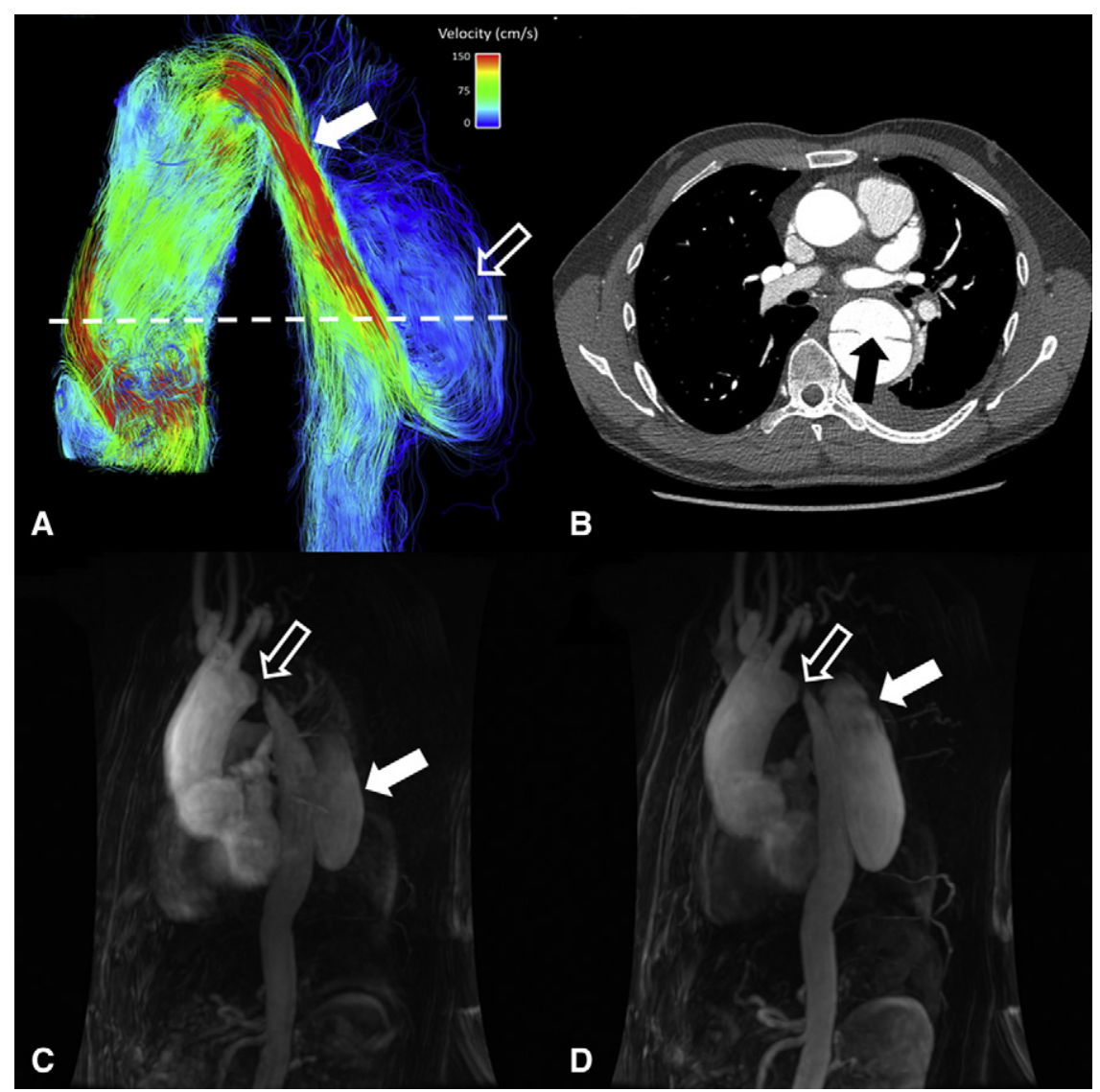

FIGURE 4. A 40-year-old man with acute type B aortic dissection. A, Color-coded streamline visualization during mid-systole showing flow acceleration (open arrow) in the proximal descending aorta. A large amount of the flow in the proximal descending thoracic aorta is directed into the FL through a large intimal tear, seen on an axial computed tomography angiography image at the level indicated by the dashed line (B, arrow). The flow into the FL is characterized by a large vortex (A, closed arrow) that results in primarily retrograde flow in the FL, as also seen on 2 subtracted maximum intensity projection images ( $\mathrm{C}$ and $\mathrm{D}$, closed arrows) acquired with time-resolved, contrast-enhanced MRA. The maximum intensity projection images (C and D) also confirm the presence of a severe narrowing in the proximal descending thoracic aorta (open arrows), which is the source of the flow acceleration observed with $4 \mathrm{D}$ MR velocity mapping (A).

Dissections were observed in 44 of 52 analysis planes and 34 of 52 segments. Retrograde flow was present on 41 of 52 analysis planes of the nondissected or TL and 20 of 22 analysis planes of the FL. In the TL, retrograde flow was judged strong in 12 of 41 and normal in 29 of 41 analysis planes. The retrograde flow in the TL was predominantly vortical in 25 of 41 and laminar in 16 of 41 analysis planes. In the FL, retrograde flow was laminar in 9 of 20 analysis planes compared with predominantly vortical in 11 of 20 analysis planes. Of note, retrograde flow in the FL occurred earlier than in the TL in 14 of 20 analysis planes (Figure 1). For both maximum systolic time frame and early diastole, the flow in the TL was earlier (27/34) or occurred at the same time (7/34) compared with the FL.

\section{Quantitative Analysis}

The results of the quantitative analysis of flow at each of the analysis planes are summarized in Table 2. Total flow per cardiac cycle and peak flow briefly were higher in the
TL than in the FL $(P<.01)$. Retrograde flow was less in the TL than in the FL $(P \leq .01)$. Time to peak flow in the TL occurred later than in the FL $(P=.05-.08)$.

\section{DISCUSSION}

We have demonstrated the feasibility of performing qualitative and quantitative analysis of the alterations in flow in the TL and FL of thoracic aortic dissections using 4D flow MRI. We demonstrated the feasibility of acquiring similar information on flow dynamics in aortic dissections at 2 institutions using Cartesian and non-Cartesian 4D flow MRI techniques. A major advantage of using 4D flow MRI, compared with 2D flow MRI, is that the entire thoracic aorta is imaged in a single acquisition. These acquisitions are reasonable in length and easily integrated with routine clinical MRI studies.

In this study, flow in the TL was primarily laminar, as reported in previous studies performed with Doppler echocardiography ${ }^{17}$ and 2D PC MRI. ${ }^{10,11}$ Of note, we found 


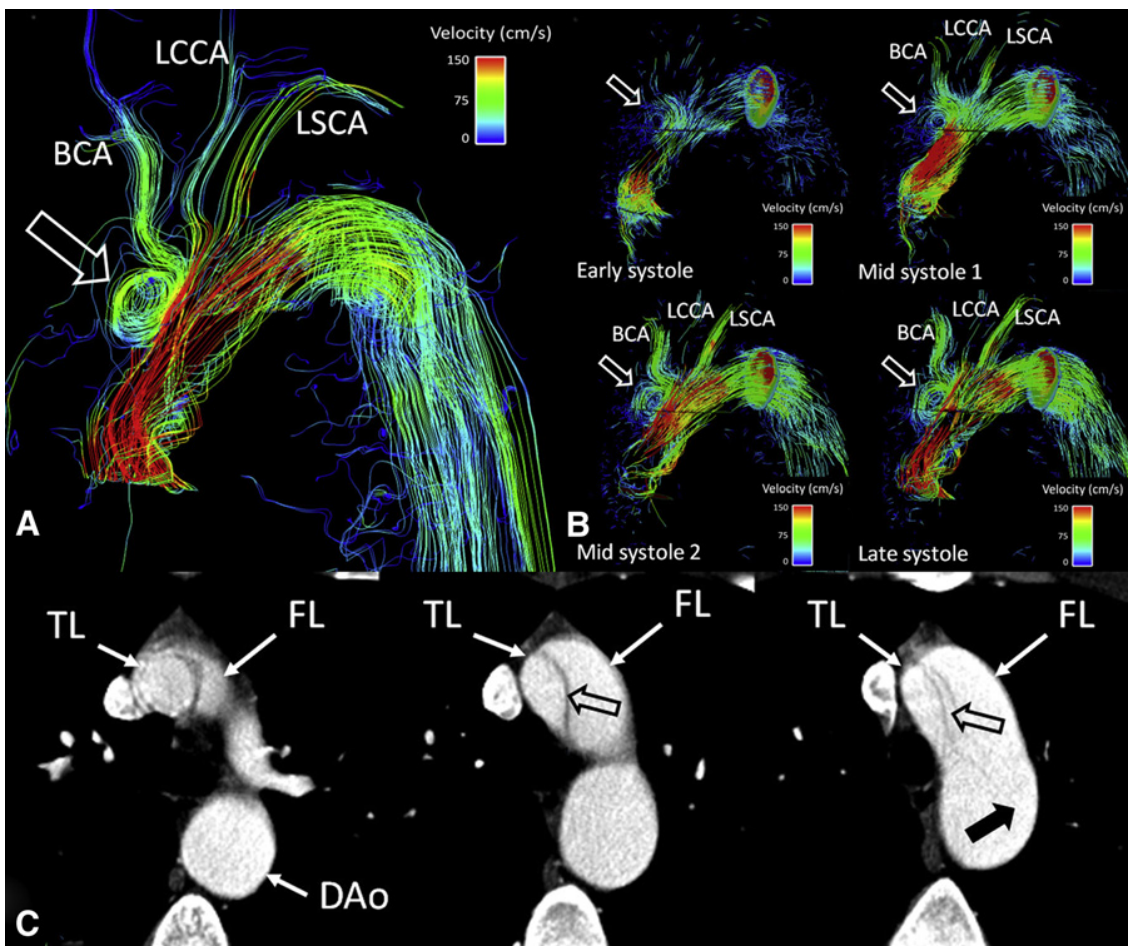

FIGURE 5. A 26-year-old man with prior type A aortic dissection repair. Streamline visualization (A) and time-resolved particle traces in the proximal aortic arch (B) show vortical flow patterns (arrows) in the residual FL, proximal to the origin of the brachiocephalic artery. C, Axial image from computed tomography angiography showing relationship of TL, FL, and intimal flap (open arrow). BCA, Brachiocephalic artery; LCCA, left common carotid artery; $L S C A$, left subclavian artery; $T L$, true lumen; $F L$, false lumen; $D A o$, descending aorta.

a relatively high number of vortical streamline and particle path patterns in both TL and FL. This is in distinction to the normal aortic flow patterns in aortic dissection reported previously. ${ }^{18,19}$ Likewise, the number of macroscopically described vortices is lower than the high percentage of inplane rotational velocities noted by Hope and colleagues ${ }^{13}$ in ascending aorta aneurysms.

The presence of complex, abnormal flow patterns in the FL is concordant with the nonlaminar flow patterns observed by Mohr-Kahaly and colleagues ${ }^{17}$ with Doppler and the spectral broadening with 2D PC reported by Strotzer and colleagues. ${ }^{10}$ The ability to derive secondary biomarkers such as Reynolds' numbers ${ }^{20}$ or wall shear forces from the acquired 4D velocity field could provide the basis for translating such biomechanical markers into clinical practice. These new features derived from 4D flow imaging may help provide a better predictor for long-term follow-up and possible complications. ${ }^{21}$

The frequency of systolic backward flow in the FL in this study was more frequent than that reported by Strotzer and colleagues, ${ }^{10}$ most likely because of differences in patient populations. Alternatively, this could be related to the fact that we evaluated the entire thoracic aorta with 4D flow MRI, rather than a single 2D plane in the distal descending thoracic aorta at the level of the diaphragm. The presence of systolic retrograde flow in the FL in the more cephalad descending thoracic aorta may be due to the early reflection of the pulse wave in the FL from the obstructed more caudal aorta. The presence of retrograde flow during systole in the FL also may be indicative of distal reentry pathways at the distal end of the FL with higher pressure in the distal aorta and distal FL causing relative compression of those

TABLE 2. Quantitative flow analysis through ascending aorta, aortic arch, and descending aorta

\begin{tabular}{|c|c|c|c|c|c|c|c|}
\hline & \multirow{2}{*}{$\begin{array}{l}\text { Ascending } \\
\text { aorta }\end{array}$} & \multicolumn{2}{|c|}{ Aortic arch } & \multicolumn{2}{|c|}{ Descending aorta 1} & \multicolumn{2}{|c|}{ Descending aorta 2} \\
\hline & & TL & FL & TL & FL & TL & FL \\
\hline Flow & $67 \pm 19 \mathrm{~mL} /$ beat & $35 \pm 12 \mathrm{~mL} /$ beat & $37 \pm 12 \mathrm{~mL} /$ beat* & $35 \pm 8 \mathrm{~mL} /$ beat & $4 \pm 8 \mathrm{~mL} /$ beat* & $35 \pm 8 \mathrm{~mL} /$ beat & $7 \pm 11 \mathrm{~mL} / \mathrm{beat} *$ \\
\hline $\begin{array}{c}\text { Retrograde } \\
\text { flow }\end{array}$ & $7 \% \pm 4 \%$ & $7 \% \pm 7 \%$ & $5 \% \pm 8 \% *$ & $3 \% \pm 4 \%$ & $42 \% \pm 24 \% *$ & $3 \% \pm 4 \%$ & $29 \% \pm 26 \% *$ \\
\hline Peak flow & $380 \pm 82 \mathrm{~mL} / \mathrm{s}$ & $185 \pm 59 \mathrm{~mL} / \mathrm{s}$ & $185 \pm 50 \mathrm{~mL} / \mathrm{s}^{*}$ & $170 \pm 70 \mathrm{~mL} / \mathrm{s}$ & $64 \pm 41 \mathrm{~mL} / \mathrm{s}^{*}$ & $170 \pm 70 \mathrm{~mL} / \mathrm{s}$ & $73 \pm 52 \mathrm{~mL} / \mathrm{s}^{*}$ \\
\hline $\begin{array}{l}\text { TTP flow } \\
\text { volume }\end{array}$ & $126 \pm 27 \mathrm{~ms}$ & $160 \pm 33 \mathrm{~ms}$ & $168 \pm 48 \mathrm{~ms} \dagger$ & $172 \pm 54 \mathrm{~ms}$ & $127 \pm 42 \mathrm{~ms} \ddagger$ & $172 \pm 54 \mathrm{~ms}$ & $133 \pm 49 \mathrm{~ms}^{*}$ \\
\hline
\end{tabular}

$T L$, True lumen; $F L$, false lumen; $T T P$, time to peak. $* P<.05 . \dagger P=.064 . \ddagger P=.077$. 
portions of the TL with lower pressure. Dynamic obstruction due to pressure-dependent movement of the intimal flap can cause transient obstruction of flow through the TL during systole. ${ }^{10,22}$ Further extending the craniocaudal field of view, to include the entire thoracic and abdominal aorta, may help elucidate these potential causes. Identifying and validating imaging biomarkers of impending dynamic TL obstruction would have significant clinical application. Likewise, many have sought to identify morphologic predictors of subsequent aortic aneurysm, and it seems likely that incorporating hemodynamic parameters obtained with 4D flow MRI will improve predictions. ${ }^{23-25}$

Increasing the craniocaudal extension of the 4D flow MRI acquisition to include the mesenteric and renal arteries also would enable an assessment of the relative flow to these vessels and relative contributions from the TL and FL. Although these techniques have not been validated for this specific application, flow quantification with 4D flow MRI techniques have been validated in flow phantoms, animal models, and other vascular territories in humans. ${ }^{26}$

The lack of long-term follow-up data to determine the prognostic significance of these alterations in flow patterns is a limitation of this study, but was not part of its central design. The single case in which a second scan was performed is not sufficient for any generalization about the features that could be predictive of future outcome.

Another limitation of this study is the lower signal in the FL, which limited our analysis of the flow features in the FL to systole and early diastole because the flow patterns in the FL during late diastole could not be differentiated from noise. Future work will focus on data acquisition strategies ${ }^{15}$ with an increased velocity-encoding sensitivity spectrum to improve the measurement and visualization of regions with low flow, such as the FL. This could then enable us to perform additional quantitative analyses in both the TL and FL.

Although flow through large intimal tears was evident in a minority of the cases, the spatial and temporal resolution of the 4D flow MRI techniques used in this study are inadequate to evaluate flow across the small intimal tears frequently encountered in chronic aortic dissection. However, it is not clear whether localization of these small intimal tears is important in determining prognosis.

In this study, all 4D flow MRI acquisitions were performed after the administration of gadolinium-based contrast agents because of the improved signal-to-noise ratio for these types of sequences when performed after contrast administration. However, the use of contrast material is not necessary for these sequences to be used. In fact, 4D flow MRI sequences are used for noncontrast-enhanced MRA. ${ }^{27}$ Therefore, renal function would not be a contraindication to the acquisition of this type of study. Patients with contraindications to MRI in general would not be able to undergo 4D flow MRI.

\section{CONCLUSIONS}

We have shown that it is possible to acquire similar 4D flow MRI data using scanners from different manufacturers and different acquisition techniques. This indicates that future prospective studies investigating the prognostic implications of these alterations in flow can be performed at multiple centers using different 4D flow MRI techniques. Larger, multicenter studies also would be useful for further investigating any potential impact of the inherent differences between Cartesian and non-Cartesian techniques, including differences in coverage, spatial resolution, and temporal resolution.

The authors thank Adriana Komancsek and Manuela Rick for assistance in acquiring studies at the University of Wisconsin; Alejandro Muñoz del Rio, PhD, for assistance with the statistical analysis; and Jon Matsumura, MD, for reviewing the manuscript and providing valuable comments before submission.

\section{References}

1. Collins JS, Evangelista A, Nienaber CA, Bossone E, Fang J, Cooper JV, et al. Differences in clinical presentation, management, and outcomes of acute type a aortic dissection in patients with and without previous cardiac surgery. Circulation. 2004; 110:II237-42.

2. Suzuki T, Mehta RH, Ince H, Nagai R, Sakomura Y, Weber F, et al. Clinical profiles and outcomes of acute type B aortic dissection in the current era: lessons from the International Registry of Aortic Dissection (IRAD). Circulation. 2003;108(Suppl 1):II312-7.

3. Tsai TT, Evangelista A, Nienaber CA, Myrmel T, Meinhardt G, Cooper JV, et al Partial thrombosis of the false lumen in patients with acute type B aortic dissection. $N$ Engl J Med. 2007;357:349-59.

4. Januzzi JL, Marayati F, Mehta RH, Cooper JV, O'Gara PT, Sechtem U, et al. Comparison of aortic dissection in patients with and without Marfan's syndrome (results from the International Registry of Aortic Dissection). Am J Cardiol. 2004;94:400-2.

5. Debakey ME, Henly WS, Cooley DA, Morris GC Jr, Crawford ES, Beall AC Jr. Surgical management of dissecting aneurysms of the aorta. J Thorac Cardiovasc Surg. 1965;49:130-49.

6. Daily PO, Trueblood HW, Stinson EB, Wuerflein RD, Shumway NE. Management of acute aortic dissections. Ann Thorac Surg. 1970;10:237-47.

7. Nienaber CA, Rousseau H, Eggebrecht H, Kische S, Fattori R, Rehders TC, et al. Randomized comparison of strategies for type B aortic dissection: the INvestigation of STEnt Grafts in Aortic Dissection (INSTEAD) trial. Circulation. 2009; 120:2519-28.

8. Tefera G, Acher CW, Hoch JR, Mell M, Turnipseed WD. Effectiveness of intensive medical therapy in type B aortic dissection: a single-center experience. $J$ Vasc Surg. 2007;45:1114-9.

9. Mohri M, Nagata Y, Hisano R, Koyanagi S, Hirata T, Nakamura M. Detection of different blood flow patterns in the true and false lumina with aortic root dissection by pulsed Doppler echocardiography. Clin Cardiol. 1985;8: 225-7.

10. Strotzer M, Aebert H, Lenhart M, Nitz W, Wild T, Manke C, et al. Morphology and hemodynamics in dissection of the descending aorta. Assessment with MR imaging. Acta Radiol. 2000;41:594-600.

11. Bogren HG, Underwood SR, Firmin DN, Mohiaddin RH, Klipstein RH, Rees RS et al. Magnetic resonance velocity mapping in aortic dissection. $\mathrm{Br} J$ Radiol. 1988;61:456-62.

12. Chang JM, Friese K, Caputo GR, Kondo C, Higgins CB. MR measurement of blood flow in the true and false channel in chronic aortic dissection. J Comput Assist Tomogr. 1991;15:418-23.

13. Hope TA, Markl M, Wigstrom L, Alley MT, Miller DC, Herfkens RJ. Comparison of flow patterns in ascending aortic aneurysms and volunteers using fourdimensional magnetic resonance velocity mapping. J Magn Reson Imaging 2007;26:1471-9. 
14. Gu T, Korosec FR, Block WF, Fain SB, Turk Q, Lum D, et al. PC VIPR: a highspeed 3D phase-contrast method for flow quantification and high-resolution angiography. AJNR Am J Neuroradiol. 2005;26:743-9.

15. Johnson KM, Markl M. Improved SNR in phase contrast velocimetry with fivepoint balanced flow encoding. Magn Reson Med. 2010;63:349-55.

16. Stalder AF, Russe MF, Frydrychowicz A, Bock J, Hennig J, Markl M. Quantitative 2D and 3D phase contrast MRI: optimized analysis of blood flow and vessel wall parameters. Magn Reson Med. 2008;60:1218-31.

17. Mohr-Kahaly S, Erbel R, Rennollet H, Wittlich N, Drexler M, Oelert H, et al. Ambulatory follow-up of aortic dissection by transesophageal two-dimensional and color-coded Doppler echocardiography. Circulation. 1989;80:24-33.

18. Kilner PJ, Yang GZ, Mohiaddin RH, Firmin DN, Longmore DB. Helical and retrograde secondary flow patterns in the aortic arch studied by three-directional magnetic resonance velocity mapping. Circulation. 1993;88:2235-47.

19. Bogren HG, Buonocore MH. 4D magnetic resonance velocity mapping of blood flow patterns in the aorta in young vs. elderly normal subjects. J Magn Reson Imaging. 1999;10:861-9.

20. Reynolds O. An experimental investigation of the circumstances which determine whether the motion of water shall be direct or sinuous, and of the law of resistance in parallel channels. Philosoph Trans $R$ Soc Lond. 1883;174: 935-82.
21. Stalder AF, Frydrychowicz A, Russe MF, Korvink JG, Henning J, Markl M. Blood flow in the healthy aorta: turbulent or not? Proc Intl Soc Mag Reson Med. 2009; 17:3850.

22. Iwai F, Sostman HD, Evans AJ, Nadel SN, Hedlund LW, Beam CA, et al. Cine phase-contrast magnetic resonance imaging for analysis of flow phenomena in experimental aortic dissection. Invest Radiol. 1991;26:1071-8.

23. Kato M, Bai H, Sato K, Kawamoto S, Kaneko M, Ueda T, et al. Determining surgical indications for acute type B dissection based on enlargement of aortic diameter during the chronic phase. Circulation. 1995;92:II107-12.

24. Immer FF, Krahenbuhl E, Hagen U, Stalder M, Berdat PA, Eckstein FS, et al. Large area of the false lumen favors secondary dilatation of the aorta after acute type A aortic dissection. Circulation. 2005;112:I249-52.

25. Song JM, Kim SD, Kim JH, Kim MJ, Kang DH, Seo JB, et al. Long-term predictors of descending aorta aneurysmal change in patients with aortic dissection. J Am Coll Cardiol. 2007;50:799-804.

26. Markl M, Wallis W, Harloff A. Reproducibility of flow and wall shear stress analysis using flow-sensitive four-dimensional MRI. J Magn Reson Imaging. 2011; 33:988-94.

27. Francois CJ, Lum DP, Johnson KM, Landgraf BR, Bley TA, Reeder SB, et al. Renal arteries: isotropic, high-spatial-resolution, unenhanced MR angiography with three-dimensional radial phase contrast. Radiology. 2011;258:254-60. 